\title{
Reducing Lumbar Discogenic Back Pain and Disability with Intradiscal Injection of Bone Marrow Concentrate: 5-year Follow-up
}

\author{
Kenneth Pettine M. D. ${ }^{1}$, Maxwell Dordevic ${ }^{1, *}$, Michael Hasz M. D. ${ }^{2}$ \\ ${ }^{1}$ Research and Development, Celling Biosciences, Austin, USA \\ ${ }^{2}$ Spine Institute, Virginia Spine Institute, Reston, USA
}

\begin{abstract}
Background Context: Surgical treatments of discogenic lumbar back pain are fusion or lumbar artificial disc replacement. Studies comparing lumbar fusion with nonsurgical treatment found no difference in clinical results. Studies comparing lumbar fusion with lumbar artificial disc replacement have had mixed results. In a study with 12-month follow-up, our colleagues reported that intradiscal injections of autologous bone marrow concentrated cells resulted in substantial reductions in pain and disability without treatment complications or other adverse events. Purpose: This article reports a 5-year follow-up of treating lumbar discogenic back pain and disability with bone marrow concentrate. Study Design/Setting: Prospective, open-label, single-center case series. Patient Sample: The initial 26 participants were all surgical candidates according to their history of low back pain, nonsurgical treatment, and measurements of pain, disability, and disc degeneration. Outcome Measures: Visual Analog Scale of pain, and Oswestry Disability Index. Methods: Study design and clinical protocol, bone marrow collection and processing, and intradiscal injection were as previously described in the initial report. The study did not receive any outside funding. The disposable aspiration kits for the BMC injections, which cost about $\$ 20$ each, were provided without charge by Celling Biosciences, Austin, Texas. Results: Of the initial 26 participants, six proceeded to surgery within 3 years of follow up. Of the remaining 20,19 were available for follow-up at 5 years. Absolute and percentage reductions in pain and disability scores were sustained through the 5 -year follow-up. No adverse events were reported through the 5 years. Conclusions: It may be reasonable to consider injecting participants who have discogenic back pain at one or two levels with bone marrow concentrate before they proceed to surgery.
\end{abstract}

Keywords Lumbar Discogenic Back Pain, Bone Marrow Concentrate, Fusion, Disc Replacement

\section{Introduction}

A fact sheet from the United States Bone and Joint Initiative summarizing the burden of musculoskeletal diseases states that one in four adults in the United States suffers from chronic low back pain, with a cost of more than $\$ 250$ billion in treatment and lost wages [1]. Surgical treatments of lumbar discogenic back pain are fusion or lumbar artificial disc replacement (LADR) [2, 3, 4]. A 2-year follow-up study [5] and a 4-year follow-up study [6] compared lumbar fusion with nonsurgical care. They reported no differences in clinical results. One study with a 2- year follow-up [7] concluded that LADR is as least as good as fusion. Another two studies with a 2-year follow-up

* Corresponding author:

mdordevic@utexas.edu (Maxwell Dordevic)

Published online at http://journal.sapub.org/ajscr

Copyright (C 2018 The Author(s). Published by Scientific \& Academic Publishing

This work is licensed under the Creative Commons Attribution International

License (CC BY). http://creativecommons.org/licenses/by/4.0/
$[2,3]$ reported that LADR is superior to fusion. However, one of these studies continued to a 7-year follow-up [7,8]. This study concluded that outcomes after LADR were similar to those after fusion. A 5 to 10 -year follow-up study [9] of LADR clinical results showed substantial improvements in VAS and ODI from baseline at all follow-ups. However, this study also reported that these improvements deteriorated from 48 months after LADR. Furthermore, complications occurred in 26 (14.4\%) of the 181 participants who were followed- up.

In 2015, we [10] reported a 1-year follow-up about the use of intradiscal injections of autologous bone marrow concentrated cells (BMC) to treat moderate to severe discogenic back pain in one or two levels in 26 participants. In a single, 45-minute outpatient procedure done under conscious sedation, bone marrow cells were aspirated from the iliac crest, concentrated by centrifugation, and injected into the nucleus pulposus of one or two symptomatic, degenerated discs. The participants had had a history of least 6 months of low back pain and at least 3 months of nonsurgical treatment without resolution. The mean 
pretreatment pain score as measured by the $0 \mathrm{~mm}$ to 100 mm Visual Analog Scale (VAS) [11] was $79.3 \mathrm{~mm}$, and the mean pretreatment disability score as measured by the $0 \%$ to $100 \%$ Oswestry Disability Index (ODI) $[12,13]$ was $56.5 \%$. They also had a grade of 4 or greater on the 8 -grade modified Pfirrmann MRI [14] classification, indicating moderate to severe disc dehydration and degeneration. All were surgical candidates.

By 3 months, the mean VAS and ODI scores were 29.2 $\mathrm{mm}$ and $22.8 \%$, statistically significant decreases sustained through 1 year. By the end of the year, 24 (92\%) of the 26 participants had not proceed to surgery. Of these, 20 had an MRI to assess the change in Pfirrmann grade. Eight (40\%) of these 20 had decreased degeneration in their treated discs as shown by a decrease of at least one Pfirrmann grade. The other 12 had no change.

Although participant age and gender had little effect on reductions in pain and disability, the concentration of mesenchymal stem cells did. At 3 and 6 months after injection, participants receiving of at least 2,000 colony forming units of mesenchymal stem cells per milliliter experienced substantially faster and greater reductions in VAS and ODI scores than those receiving fewer cells. However, the differences between these two groups were not statistically significantly different at 1 year.

We then reported on 2 and 3-year follow-ups [15, 16]. By the end of the second and third years, the decreases in VAS and ODI scores that had been observed at the end of the first year were sustained in the participants who had not undergone surgery. No adverse events were reported through 3 years.

Between the first and second years, three participants underwent surgery. Between the second and third years, another participant underwent surgery. Thus, through 3 years of follow-up, $20(77 \%)$ participants of the starting group of 26 avoided surgery.

Here we report on the findings of a 5-year follow-up.

\section{Materials and Methods}

Study materials and methods were as described initially [10]. All participants provided written informed consent according to the form provided by Western Institutional Review Board, Puyallup, Washington (clinical study protocol approval number 20120085). The $\$ 5,000$ per participant cost of the BMC treatment and costs of subsequent follow-ups were provided at no charge. The study did not receive any outside funding. The disposable aspiration kits for the BMC injections, which cost about $\$ 20$ each, were provided without charge by Celling Biosciences, Austin, Texas.

For the 5-year follow-up, the remaining participants underwent VAS and ODI scoring, and they were asked how they felt and about how often they took opioid pain relievers. The six participants who progressed to surgery after BMC injection were contacted about they felt and how often they took opioid pain relievers. The study did not receive any outside funding.

\section{Results}

\subsection{Participant Retention}

Of the 20 participants who underwent BMC injection and had not proceeded to surgery, one could not be located and was lost to follow-up after the 3-year report, for $95 \%$ follow-up.

\subsection{Participant-reported Outcome Measures}

Absolute and percentage reductions in VAS and ODI scores were sustained through the 5 -year follow-up (Fig. 1 and Table 1, respectively). The 5-year mean VAS and ODI scores were both statistically significantly less than the 3 -year scores. At the 5-year follow-up, eight (42\%) of the 19 participants who had not proceeded to surgery reported that their back pain was either $90 \%$ reduced or to within pain and disability scores typically reported by adults ages 40 years and older unaffected by back pain, a VAS of $2 \mathrm{~mm}$ or less and an ODI of $10 \%$ or less [17]. From 3 years to 5 years, 5 of the 19 participants had increased disability as shown by increases in ODI scores from 3 to 5 years: $0 \%$ to $6 \% ; 4 \%$ to $10 \%$; $6 \%$ to $10 \% ; 12 \%$ to $14 \%$; and $14 \%$ to $22 \%$.

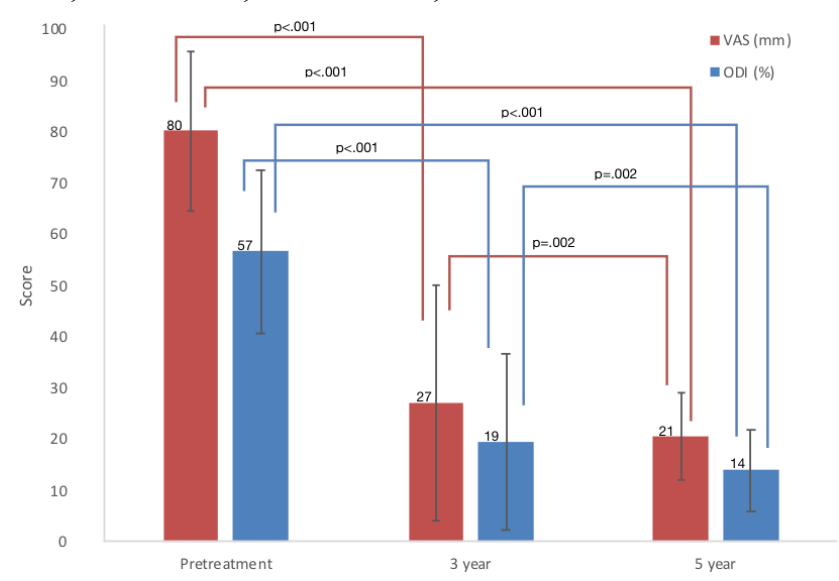

Mean (SD) VAS and ODI scores at pretreatment [10] and at 3-year [16] and 5 -year (this article) follow-ups $(\mathrm{n}=19)$. SD, standard deviation; VAS, Visual Analog Scale; ODI, Oswestry Disability Index [1].

Figure 1

Table 1

\begin{tabular}{|c|c|c|c|}
\hline \multicolumn{2}{|c|}{ Score } & \multicolumn{2}{c|}{ Comparison } \\
\hline & $\begin{array}{c}\text { 3-year and } \\
\text { pretreatment }\end{array}$ & $\begin{array}{c}\text { 5-year and } \\
\text { pretreatment }\end{array}$ & $\begin{array}{c}\text { 5-year and } \\
\text { 3-year }\end{array}$ \\
\hline VAS (mm) & $66(23) \mathrm{p}<.001$ & $74(9) \mathrm{p}<.001$ & $7(9) \mathrm{p}=.002$ \\
\hline ODI $(\%)$ & $67(17) \mathrm{p}<.001$ & $75(8) \mathrm{p}<.001$ & $26(8) \mathrm{p}=.002$ \\
\hline
\end{tabular}

SD, standard deviation; VAS, Visual Analog Scale; ODI, Oswestry Disability Index $[12,13]$. The $100 \%$ values used to compute these percentage decreases were taken from data to calculate the mean values on Fig. 1 
At the end of 5 years, four of the six participants who had proceeded to surgery reported taking opioid pain relievers frequently (three to four times weekly), and two of the 19 who did not proceed to surgery reported taking opioids occasionally (three to four times monthly). The other participants who did not proceed to surgery reported no use of opioids.

\subsection{Adverse Events}

As previously reported [16], there were no adverse events through 3-year follow-up. For the 19 participants who underwent $\mathrm{BMC}$ injection and were evaluated at the 5-year follow-up, no adverse events were reported between the 3 -year and 5-year follow-ups.

\subsection{Proceeding to Surgery}

As previously reported [16], six of the original 26 participants proceeded to surgery through 3 years of follow-up. With the possible exception of the one participant who was lost to 5-year follow-up, no additional participants proceeded to surgery after the 3-year follow-up. Through 5 years, two of the six participants who proceeded to surgery after BMC injection had good surgical outcomes in that they felt better than they did pretreatment.

\section{Discussion}

Of the 20 participants who initially underwent BMC injection and did not proceed to surgery, 19 were followed up for 5 years. Overall, pain (VAS scores) and disability (ODI scores) continued to decrease from scores reported in the 3-year follow-up [16]. The increases in disability reported at 5 years in 5 of these 19 participants were only slight. In contrast, only two of the six participants who proceeded to surgery within 3 years after the BMC injection had good surgical outcomes. At 5 years, opioid use was substantially less in the BMC-only participants compared with those six who proceeded to surgery.

Meanwhile, no participant proceeded to surgery after the 3-year follow-up. Compared with pretreatment pain and disability, no participant was made worse from the BMC injections. No adverse events were reported since the 3-year follow-up. Thus, through 5 years, no serious complications or adverse events were associated with the BMC injection.

The results in this study of using bone marrow concentrate to treat discogenic back pain with 5- year follow-up were superior to the 2-year results of lumbar fusion or LADR [2, 3, 7]. Inasmuch as studies $[5,6]$ comparing lumbar fusion with nonsurgical care reported no difference in clinical results, $\mathrm{BMC}$ injection appears to be superior to lumbar fusion surgery in cases of chronic discogenic back pain. The continuing success for most of the 26 initial participants indicates that $\mathrm{BMC}$ injection is sustained for as long as 5 years with minimal safety concerns. And as noted, the cost of the BMC treatment was $\$ 5,000$. This cost was considerably less than the cost of fusion, $\$ 50,000$ to $\$ 75,000$, or of lumbar artificial disk replacement, $\$ 35,000$ to $\$ 45,000$.

\section{Conclusions}

To our knowledge, our previous reports $[10,15,16]$ and this report are the only ones about use of BMC to treat discogenic lumbar back pain and disability. It remains to be determined if the favorable results of this small, preliminary study will continue to be sustained. The study lacked a randomized control group, and MRIs were not done long-term. Nevertheless, we conclude that intradiscal treatment with bone marrow concentrate offers a promising approach to treating lumbar back discogenic pain. It may be reasonable to consider treating patients with who have discogenic back pain at one or two levels with bone marrow concentrate before they proceed to fusion surgery or to artificial disc replacement.

\section{REFERENCES}

[1] United States Bone and Joint Initiative. By the numbers: musculoskeletal back pain: back and neck disorders, injuries, and disk disorders. Available at: usbji.org Accessed June 4, 2018.

[2] Gornet MF, Burkus JK, Dryer RF, et al. Lumbar disc arthroplasty with MAVERICK Disc versus stand-alone interbody fusion: a prospective, randomized, controlled, multicenter investigational device exemption trial. Spine 2011; 36(25): E1600-E1611.

DOI: 10.1097/BRS.0b013e318217668f.

[3] Zigler J, Delamarter R, Spivak JM, et al. Results of the prospective, randomized, multicenter food and drug administration investigational device exemption study of the ProDisc (R)-L total disc replacement versus circumferential fusion for the treatment of 1-level degenerative disc disease. Spine 2007; 32(11): 1155-1162, discussion 163. DOI: 10.1097/BRS.0b013e318054e377.

[4] Phillips FM, Slosar PJ, Youssef JA et al. Lumbar spine fusion for chronic low back pain due to degenerative disc disease a systematic review. Spine 2013; 38(7): E409-E422. DOI: 10.1097/BRS.0b013e3182877f11.

[5] Fritzell P, Hägg O, Wessberg P, et al. 2001 Volvo Award winner in clinical studies: Lumbar fusion versus nonsurgical treatment for chronic low back pain: a multicenter randomized controlled trial from the Swedish Lumbar Spine Study Group. Spine 2001; 26(23): 2521- 2532.

[6] Brox JI, Nygaard ØР, Holm I, et al. Four-year follow-up of surgical versus non-surgical therapy for chronic low back pain. Ann Rheum Dis 2010; 69(9): 1643-1648. DOI: $10.1136 /$ ard.2009.108902.

[7] Blumenthal S, McAfee PC, Guyer RD, et al. A prospective, randomized, multicenter Food and Drug Administration investigational device exemptions study of lumbar total disc replacement with the CHARITÉTM artificial disc versus lumbar fusion: part I: evaluation of clinical outcomes. Spine. 2005; 30(14): 1565-1575. 
Kenneth Pettine M. D. et al.: Reducing Lumbar Discogenic Back Pain and Disability with Intradiscal Injection of Bone Marrow Concentrate: 5-year Follow-up

DOI:10.1097/01.brs.0000170587.32676.0e. Erratum in Spine 2005; 30(20): 2356.

[8] ProDisc-C total disc replacement versus anterior cervical discectomy and fusion for single- level symptomatic cervical disc disease: seven-year follow-up of the prospective randomized U.S. Food and Drug Administration Investigational Device Exemption Study. Janssen ME, Zigler JE, Spivak JM, et al. J Bone Joint Surg Am 2015.4; 97(21): 1738-1747. DOI: 10.2106/JBJS.N.01186.

[9] Siepe CJ, Heider F, Wiechert K, Hitzl W, Ishak B, Mayer MH. Mid- to long-term results of total lumbar disc replacement: a prospective analysis with 5- to 10 -year follow-up. Spine $\mathrm{J}$ 2014; 14(8): 1417-1431. DOI: 10.1016/j.spinee.2013.08.028.

[10] Pettine KA, Murphy MB, Suzuki RK, et al. Percutaneous injection of autologous bone marrow concentrate cells significantly reduces lumbar discogenic pain through 12 months. Stem Cells 2015; 33(1): 146-156.

DOI: https://doi.org/10.1002/stem.1845.

[11] Scott J, Huskisson EC. Vertical or horizontal visual analogue scales. Ann Rheum Dis 1979; 38(6): 560. DOI: http://dx.doi.org/10.1136/ard.38.6.560.

[12] Fairbank JC, Couper J, Davies JB, et al. The Oswestry low back pain disability questionnaire. Physiotherapy 1980; 66(8): 271-273.
[13] Fairbank JC, Pynsent PB. The Oswestry Disability Index. Spine 2000; 25(22): 2940-2953.

[14] Pfirrmann CW, Metzdorf A, Zanetti M, et al. Magnetic resonance classification of lumbar intervertebral disc degeneration. Spine 2001; 26(17): 1873-1878.

[15] Pettine K, Suzuki R, Sand T, Murphy M. Treatment of discogenic back pain with autologous bone marrow concentrate injection with minimum two year follow-up. Int Ortho. 2016; 40: 135-140.

DOI: https://doi.org/10.1007/s00264-015-2886-4.

[16] Pettine KA, Suzuki RK, Sand TT, et al. Autologous bone marrow concentrate intradiscal injection for the treatment of degenerative disc disease with three-year follow-up. Int Orthop 2017; 41(10): 2097-2103. DOI: $10.1007 / \mathrm{s} 00264-017-3560-9$.

[17] Tonosu J, Takeshita K, Hara N, et al. The normative score and the cut-off value of the Oswestry Disability Index (ODI). Eur Spine J 2012; 21(8): 1596-1602. DOI: $10.1007 / \mathrm{s} 00586-012-2173-2177$. 